\title{
POR QUÉ RECONSIDERAR EL ENCUADRE PSICOANALITICO TRADICIONAL. UNA MIRADA RELACIONAL
}

Nora Pomeraniec Licenciada en Psicología, UDELAR Miembro Habilitante de AUDEPP Correo electrónico: nora.pomer@gmail.com ORCID: 0000-0002-0326-3581 


\section{Resumen}

Frente a la teoría del conflicto pulsional, el giro relacional en psicoanálisis, que se ha configurado durante las últimas dos décadas del siglo pasado, ha consolidado diversas corrientes de pensamiento. Estas comparten la idea medular de que nuestra mente se constituye, funciona, se enferma y recupera relacionalmente, lo que supone un cambio de paradigma metapsicológico.

No obstante, el encuadre clínico clásico se ha seguido trasmitiendo como un mantra en la formación, cuyas reglas con valor identitario quedan asociadas al ser psicoanalítico. Este trabajo visibiliza tres elementos sustantivos para su modificación: la incidencia y consideración del contexto, la centralidad de las emociones y la importancia cualitativa del vínculo terapeuta-paciente como agente de cambio. Frente a los mitos técnicos tradicionales de neutralidad, abstinencia y anonimato se postula la necesidad de una matriz de acogida terapéutica diferente: una perspectiva empática, un posicionamiento dialógico, cálido, humilde, humanista, igualitario y una hermenéutica de la confianza por el psicoterapeuta en esa díada singular que conforma con cada paciente.

Palabras clave: contextualismo, psicoanálisis relacional, emoción, mito clínico.

\section{Why rethink the traditional psychoanalytic approach. A relational outlook \\ Abstract}

Facing the drive conflict theory, the relational turn in psychoanalysis, which has emerged during the last two decades in the past century, has consolidated different schools of thought. These agree on a shared core idea: our mind is created, functions, becomes ill, and recovers relationally. This constitutes a metapsychological paradigm shift.

Nevertheless, the classic clinical approach has been conveyed as if it were a mantra so much so that to be considered a clinical psychoanalist you should follow their rules. This paper aims to make visible three substantial elements for its modification: the incidence and consideration of the context, the relevance of emotions, and the qualitative importance of the therapist-patient bond as a change agent. Faced with the traditional technical myths of neutrality, abstinence, and anonymity, there is a need for a different "therapeutic receving matrix": an empathic perspective, a dialogic position, a warm, humble, humanist and equitable position, as well as an hermeneutic of trust from the psychotherapist in this particular dyad created with each patient.

Keywords: contextualism, relational psychoanalysis, emotion, clinical myth. 
Yo soy yo y mi circunstancia, y si no la salvo a ella, no me salvo yo.

José Ortega y Gasset (1914)

Marzo de 2020. La propagación sideral del coronavirus desde una remota y desconocida ciudad asiática y su llegada a estas latitudes fue una contundente constatación de lo que Marshall McLuhan denominara la aldea global: la expansiva interdependencia humana, una relacionalidad incrementada desde la llegada de la era digital y sus avanzadas tecnologías de interconexión.

El virus y el fenómeno relacional asociado a él, el miedo al contagio, nos mostró gráfica y desmesuradamente cómo las circunstancias externas invaden nuestra vida, nuestra cotidianeidad, nuestros hábitos y emociones, y contribuyen a moldear también nuestras psicopatologías. Alteró rutinas y nos obligó a reprogramar nuestras vidas personales y laborales. Impactó en nuestro mundo emocional al generar miedo, incertidumbre, angustia, inseguridad, desconfianza..., algunas de las emociones prevalentes que acompañaron este fenómeno masivo y que se expresaron en el aumento de síntomas de depresión, insomnio, agorafobia, hipocondría, trastornos de alimentación, claustrofobia, paranoia...

El aislamiento físico, propuesto como primera medida preventiva, ingresó también — como no podía ser de otra manera— en nuestra vida profesional y nos impuso movernos de nuestra habitualidad y apelar a la videosesión como alternativa para no interrumpir tratamientos. Este nuevo contexto, que compartí con colegas y pacientes, me convirtió en inexperiente amateur y reveló que somos igualmente vulnerables. 
La realidad existe, cambia, nos cambia, marca presencia y no la podemos ignorar.

Todo fluye, nada es permanente.

Heráclito de Éfeso (siglo v a. C.)

Los tiempos van cambiando, cambian las circunstancias y también los paradigmas vigentes. Aparecen «nuevas normalidades». Esta es una de las varias paradojas de la cultura que señalara Melville Herskovits (1952): «La cultura es estable y, no obstante, la cultura es también dinámica y manifiesta continuo y constante cambio» (s. p.). Entendemos cultura en su acepción más general, como la parte del ambiente hecha por el hombre. Existe una herencia cultural, una trasmisión intergeneracional de usos, costumbres, valores, tradiciones y técnicas que nos permite beneficiarnos de la experiencia de nuestros antepasados, pero que no es ajena a la introducción de modificaciones. Lo ilustran la moda, los patrones estéticos, las nuevas alternativas de integración familiar, las herramientas informáticas, las leyes..., todas ellas manifestaciones culturales con sus ritmos diferenciados de cambio. Las teorías, como parte de ese constructo cultural, también lo hacen.

Y las nuevas teorías nos dicen que la biología no es hoy el destino. El determinismo biológico se reconoce modulado, atemperado en la moderna epigenética, que jerarquiza la importancia de las circunstancias que nos rodean (niveles de estrés, estado nutricional, contaminación ambiental) para la expresión o no de ciertos genes de los que somos portadores. Los genes solo determinan tendencias. En la misma dirección observamos el movimiento contemporáneo que realizan grupos de presión LGBT para remplazar la asignación del sexo, determinado biológicamente, por la de género, que responde a una combinatoria de variables entre las que se cuentan la autopercepción, la apariencia y la asunción de roles sociales que no coinciden necesariamente con el sexo biológico ni con 
los estereotipos culturales asignados. La relación genética y ambiental no es unívoca y permite múltiples combinatorias. Y los cambios culturales imponen nuevos criterios de normalidad y patología.

Cada individuo es portador de una historia personal, singular, única, pero que, a su vez, está atravesada, urdida, entramada con elementos de una circunstancia sociocultural compartida, que comienza desde su origen y es trasmitida por sus primeros otros.

A través de otros nos convertimos en nosotros mismos.

El ser humano, como todo organismo vivo, es un sistema abierto en desarrollo e intercambio con el medio. Ese medio tiene sus brazos ejecutores, redes relacionales que comienzan con la familia y de las que iremos formando parte, que se infiltran estructuralmente en nuestro proceso de construcción de identidad. Somos eslabones de múltiples cadenas de interrelacionalidad a distintos niveles, extraña dialéctica de ser uno mismo y ser influido por los otros, identidad e identificación.

De igual modo que los seres humanos somos desprendimiento de una matriz biológica que nos habilita al nacimiento, somos emergentes de una matriz relacional y sociocultural que se hace presente desde nuestra prehistoria, antes incluso de nuestro primer encuentro presencial con el otro: ¿concepción natural o fertilización asistida?, ¿ginecólogo o comadrona? Esta es otra de las paradojas que señala Herskovits (1952): la cultura llena y determina ampliamente el curso de nuestras vidas, nos preexiste y nos subsiste, tiene existencia propia, pero se expresa a través de los individuos. Sin embargo, raramente somos conscientes de hasta qué punto.

En la mayoría de los casos, simplemente naturalizamos y nos adaptamos inconscientemente a sus estereotipos y generamos patrones automáticos de 
respuesta que consideramos propios («Yo siempre fui así»). En otros casos, la necesidad de aceptación, reconocimiento y pertenencia es la que opera para que nos sometamos, aun críticamente, a ellos. Pero también sucede que confrontamos y nos rebelamos. La cultura nos modifica, pero también puede ser modificada por nosotros. Al igual que la herencia genética, la herencia sociocultural sufre mutaciones, experiencia que Sigmund Freud mismo, como genial innovador, propició. Difícil experiencia: querer imponer ideas disruptivas, pero simultáneamente satisfacer la necesidad y búsqueda de aceptación, reconocimiento y pertenencia a la comunidad científica, la cual demora en llegar — como en el caso de Sándor Ferenczi— o no llega nunca.

El malestar en la cultura es el rol que le asignó Freud a la realidad fáctica: el restrictivo, el limitador de la libre expresión pulsional. Quedó fuera de su análisis el papel estructurante de la cultura, del contexto, en nuestro psiquismo; el rol que tienen los otros, comenzando por la díada madre-bebé, esa matriz relacional de acogida para poder desarrollarnos y regular nuestras emociones y expectativas. A lo largo de nuestra vida sumaremos muchas otras redes relacionales (pensemos tan solo en nuestro currículum vítae), que irán dejando su impronta en nosotros, aunque las abandonemos o nos encontremos solos en una isla. El otro, real o fantaseado, siempre está. Esta idea de interacción mutua permanente, de un psiquismo bipersonal contextuado, será la que postulen las líneas del giro relacional en psicoanálisis.

El conocimiento es una aventura incierta que conlleva en sí misma el riesgo de ilusión y de error.

Edgar Morin (1999)

Si bien hoy aparece como innegable esta influencia del contexto en la constitución de nuestro psiquismo, Freud desarrolla un modelo de 
aparato psíquico individual, aislado, atemporal e inespacial, de alto nivel de abstracción, que tanto podría haber estado en la Antigua Grecia como en el Montevideo del siglo xxi y que se construye como resultado de los avatares de un conflicto pulsional endógeno que gira en torno al complejo edípico, considerado universal.

El dualismo cartesiano imperante marcaba una lógica binaria: mentecuerpo, yo - no yo, mundo interno - mundo externo, sujeto-objeto, individuo-sociedad. Esa compartimentación dicotómica constituye un artificio que delimita la especificidad del objeto de estudio al reducir el número de variables intervinientes y facilita la profundización de conocimientos segmentados. Pero no se corresponde con la realidad: integrada, compleja, heterogénea, multideterminada y mutante, y nos hace correr el riesgo de la reificación: tomar la parte por el todo y perder una mirada integral.

Desde las formulaciones de Freud ha transcurrido más de un siglo de clínica, investigación y nuevos modelos teóricos. La evolución de las ciencias y la necesaria interconexión entre ellas han cambiado la mirada en un intento de superar la rigidez de esas categorías binarias y nos permiten hablar hoy de psiconeuroinmunoendocrinología o de neuropsicoanálisis. La complementación de saberes ha cambiado la letra del psicoanálisis, pero sigue vivo el espíritu freudiano de buscar sentido, explicación y alivio al sufrimiento psíquico.

Nuestra vida psicológica no puede ser la vida de una mente aislada: se origina, crece y cambia dentro de los contextos intersubjetivos en los que nos encontramos.

D. Orange, G. Atwood y R. Stolorow (2012)

Lo dirá el psicoanálisis relacional. Y también la neurociencia a partir del descubrimiento de las neuronas espejo: nuestro cerebro es un cerebro 
social. Está equipado para trabajar en red: captando los pensamientos, intenciones y sentimientos de otros cerebros con los que interactuamos. Esto no desdibuja nuestra subjetividad, sino que la plantea en otros términos: nuestra vida mental es cocreada (Stern, 2017) y las emociones son su principio activo. La idea freudiana de la mente aislada y su organización pulsional constituye el mito fundacional del psicoanálisis.

Producto de las experiencias relacionales con nuestros primeros cuidadores van surgiendo las conclusiones emocionales inconscientes, de enorme trascendencia. Allí, en esa primera díada madre-bebé, comienza a gestarse el inconsciente prerreflexivo, un inconsciente que no es producto de la represión, sino que adquiere su carácter de tal porque se gesta sin pasar por la consciencia: «principios organizadores que operan fuera del conocimiento consciente de la persona» (Stolorow y Atwood, 2004, p. 67). La responsividad empática (o su falta) en nuestra primera matriz de acogida nos va a ir indicando qué podemos esperar de los otros: sentará las bases de nuestra autoestima, pautará patrones de relacionamiento futuros, así como dará forma a nuestra manera de percibir el mundo (amigable, hostil, inestable...); «lo sabido no pensado» (Bollas, 1987), que se expresa a través de esta memoria implícita.

El inconsciente prerreflexivo coexiste con un inconsciente dinámico, que no reprime pulsiones endógenas y sus formas de expresión, sino aquellos traumas afectivos experienciales «que fueron tapiados defensivamente porque no habían conseguido evocar una responsividad empática por parte del entorno cuidador» (Stolorow y Atwood, 2004, p. 69). Es una confusión de lenguas traumática entre las necesidades del bebé y las respuestas inadecuadas del adulto a cargo. Este desencuentro muchas veces se reproduce en la díada terapeuta-paciente y genera retraumatizaciones y resistencia al tratamiento.

La matriz intersubjetiva es el molde en el que se va fraguando nuestra vida psíquica, así como también donde irá cambiando. Sobre esta base, 
en las dos últimas décadas del siglo pasado se constituye el giro relacional en psicoanálisis (Mitchell, 2015), que reivindica tardíamente la figura de Ferenczi, quien retomara la teoría freudiana del trauma y fuera precursor de la jerarquización de la importancia de la relación paciente-analista.

Todas estas líneas de pensamiento, más allá de sus diferencias, comparten una premisa: el carácter intersubjetivo de lo intrapsíquico. Esto ya había sido señalado por Donald W. Winnicott al desplazar su foco atencional desde el infante al complejo madre-bebé; por Heinz Kohut, quien sostiene que la experiencia de sí mismo sienta sus bases en contextos de relacionalidad específicos; por René Spitz, quien observa y describe la depresión anaclítica de bebés de orfanato, privados del vínculo afectivo; y por John Bowlby, con su teoría del apego, un importante aporte a la clínica. Todos ellos partieron de hechos observables. Para constituirse como sujeto, para enfermar y también para curar se necesita de un otro.

Otra teoría - ¿otra clínica? - nos enfrenta al renovado desafío de establecer un conjunto de condiciones óptimas posibles para esa cita a ciegas que representa el encuentro con un desconocido que sufre y acude a la consulta en busca de ayuda terapéutica. Porque de eso se trata el encuentro con cada paciente: de una aventura de conocimiento y descubrimiento para ambos, más allá de las experiencias previas que podamos tener.

\section{Si nuestra única herramienta es un martillo, tenderemos a ver todos los problemas como un clavo.}

Abram Maslow (1966)

Hay quien señala que Freud fue el menos ortodoxo de los freudianos. No obstante, la tradición institucional cristalizó sus reglas técnicas al convertirlas en pilares para asegurar la pertenencia a la comunidad psicoanalítica; el apartamiento de ellas era una transgresión expresada con 
un «Eso no es psicoanálisis». ¿Puede un encuadre ser uniforme, preestablecido para todos los pacientes independientemente de su patología? Si cambian las teorías sobre el enfermar, ¿no deberíamos revisar también las teorías sobre el sanar?

Los pacientes que vienen a la consulta no vienen para conocerse: lo hacen para cambiar y sentirse mejor, para aliviar sus pesares, su sensación de vacío y desmotivación, para solucionar conflictos, superar miedos, mejorar su autoestima o sus vínculos. Estas problemáticas son más afines al Edipo-bebé abandonado y sus secuelas, que planteara Ronald Fairbairn, que al Edipo-adulto incestuoso, que inspiró a Freud. Estas dos miradas distintas sobre un mismo personaje dan origen a teorías diferentes y nos hablan de la inevitable subjetividad con que cada uno percibe y encara la realidad. Las nuevas corrientes de pensamiento psicoanalítico han desplazado su interés desde los conflictos intrapsíquicos hacia la investigación y experiencia del self, y nos llevan a interrogantes acerca de la identidad (¿quién soy yo para mí y quién para los demás?), de la autoestima (la distancia entre lo que soy o creo que soy y lo que quiero ser o creo que debo ser), de la relación con valores (proyecto parental y expectativas socioculturales) o de la relación con los otros (diferentes modelos de apego).

Junto a las patologías por conflicto aparecen las patologías por déficit, patologías del vacío, vinculadas a la insatisfacción temprana de necesidades emocionales, a la falta de una adecuada respuesta a ellas. Estas, a su vez, están reforzadas por ciertos aspectos de esta sociedad individualista, exigente, competitiva, discriminadora, de imágenes y apariencias, de maternajes delegados rápidamente por necesidades económicas o por «realización personal», de amistades virtuales por arte de un simple like o de seguidores tan evanescentes como las relaciones líquidas que describe Zygmunt Bauman (2003).

Creemos que no existe una coherencia lógica entre estas patologías y las tradicionales reglas clínicas freudianas. 
En las dos últimas décadas, las líneas de psicoanálisis relacional han planteado la necesidad de rever el vínculo terapeuta-paciente a la luz de los conocimientos adquiridos por la observación, la investigación y el seguimiento de la díada madre-bebé (Grupo de Boston), y lo han considerado un agente con potencial terapéutico en sí mismo. El trabajo clínico de Winnicott y su experiencia como pediatra lo convencieron de que, para recuperarse, algunos pacientes regresan a la dependencia en el análisis.

Creía que tales pacientes necesitan un analista preparado que los reciba en términos de Winnicott: "con preocupación maternal primaria”; en palabras de Ferenczi: "con amor"; y en las mías: con la hermenéutica de la compasión (Orange, 2006) y de la confianza. (Orange, 2013, p. 143)

No comprar el marco primero y luego crear algo o alguien apropiado para él.

D. Orange, G. Atwood y R. Stolorow (2012)

Las reglas clínicas impresionan, por momentos, como una forma de disciplinamiento impuesta por el psicoterapeuta a la que el paciente se tiene que adaptar; como esas prendas de talle único que nos prometen que se estiran con el uso o que encogen con el primer lavado.

El encuadre psicoanalítico o setting tradicional propone un marco dentro del cual se desarrolla el proceso analítico: reglas e indicaciones con las cuales los psicoterapeutas ingresamos al campo clínico. Nos dicen qué hacer aun antes de saber qué hacer. Mantener el anonimato, la abstinencia, la neutralidad, el uso del diván y limitar las intervenciones a interpretar la transferencia -instrumento central de la técnica analítica clásica- para así hacer consciente lo inconsciente y lograr insight. un posible pase al cambio psíquico. Todo ello está apoyado por una sistemática hermenéutica de 
la sospecha: nada es lo que parece. Se deja de lado la alta frecuencia de sesiones propuesta, porque el principio de realidad ya la ha desplazado.

El carácter monológico del psicoanálisis clásico y el silencio del analista en sesión descansan en la idea, trasmitida en la formación, de que minimizar sus intervenciones a momentos puntuales de interpretación de la transferencia permite el mejor despliegue del paciente de esta última sin direccionamientos ni influencias sugestivas. Esta posición es tributaria de un modelo positivista, que consideraba que el analista puede ser un observador objetivo, que la transferencia se reproduce virgen, incontaminada, indiferente al receptor, y que el silencio y la abstinencia favorecen la neutralidad. Los intersubjetivistas se encargarán de desmitificar este y otros supuestos, que consideraron ilusorios.

El primer concepto tradicional al que se oponen es el de técnica, que definen como la puesta en acción de reglas que se repiten de la misma manera rutinaria y poseen un carácter instrumental. Proponen sustitutivamente hablar de práctica, que admite un componente artesanal, creativo, permite organizarse en función de lo particular y habilita el asombro y el descubrimiento.

En las relaciones humanas no existe la neutralidad. Joan Coderch de Sans (2010)

Un supuesto que consideran falso es el de asociar el silencio a la neutralidad. El silencio también es comunicativo. Todo lo que hacemos, tanto lo que decimos como lo que callamos, incide sobre el otro y es pasible de ser interpretado, lo que no significa que sea interpretado. Permanecer en silencio durante la sesión también es hacer algo e influye en el receptor. Y si ese silencio es sistemáticamente sostenido como parte de la técnica, esa falta de retroalimentación, de respuesta emocional a su relato, puede degradar la autoestima del paciente e incluso reactivar emocionalmente 
antiguas situaciones traumáticas de soledad e incomprensión (memoria implícita). Más allá de la intención de neutralidad que guíe al analista, su actitud de asepsia comunicativa puede ser decodificada por el paciente como desinterés («Lo estoy aburriendo»), abandono («Estoy hablando solo»), indiferencia («No le importa lo que me pasa»), confusión («No sabe qué decirme»), frialdad («No le llega mi dolor») y generar desánimo, reacción terapéutica negativa, faltas a sesiones e incluso abandono del tratamiento. Sería muy soberbio de parte del psicoterapeuta que atribuyera estas reacciones exclusivamente a la psicopatología del paciente sin involucrarse en un autoanálisis situacional.

Algo similar sucede con otra regla cuestionada: la que postula la abstinencia. Trabajar con el paciente en abstinencia hace referencia a no proporcionarle satisfacciones o gratificaciones sustitutivas que, a la manera de placebos, puedan impedir que afloren a la consciencia los deseos reprimidos. La obediencia a esa regla ya indica una toma de posición del analista con respecto a una teoría (la del conflicto pulsional), lo que hace difícil entender la neutralidad desde esa perspectiva. Mientras, para el paciente esa frustración de sus necesidades («Haceme preguntas», «Tuteame») no puede representar neutralidad alguna, sino hostilidad del terapeuta, o bien le marca su propia inadecuación y le genera autocensura.

Otro tanto ocurre con la opacidad propuesta por Freud (1980) al analista de «no mostrar más de lo que le es mostrado a él» (p. 117). La necesidad de esta opacidad del analista conecta con otro supuesto de base cuestionado por el psicoanálisis relacional: considerar que un analista anónimo permite el despliegue de la transferencia incontaminada, en estado virgen, sin ningún tipo de alteración (Orange, 2012).

La transferencia no es solo producto de la mente del paciente, sino una creación conjunta entre paciente y analista. Otro tanto sucede con la contratransferencia. Más allá de sus intenciones, el terapeuta —como 
cada uno de nosotros - siempre configura lo observado de acuerdo a su subjetividad. Se revela permanente e involuntariamente. Lo hace a través de su forma de vestir, de las características de su consultorio, así como a través de sus interpretaciones, que exponen aspectos de su forma de observación, su experiencia, sus convicciones, su lenguaje y su teoría de elección. Las interpretaciones que haga muy posiblemente no coincidirían con las que haría del mismo paciente otro terapeuta. De algún modo, al ofrecerle al paciente un contenido que «nunca había pensado», el terapeuta le está proponiendo mirar a través de su propia mirada, de su perspectiva de análisis, lo que no deja de tener un componente de sugestión, en especial por la autoridad que este tiene.

Ahora bien, ¿qué le asigna a la interpretación del terapeuta un carácter mesiánico? ¿Y qué sucede frente a ella con el paciente? Si la desecha o se opone, se hablará de resistencia a la cura, al igual que sucede frecuentemente en el impasse o el abandono de la terapia. Bernard Brandschaft describe estas actitudes como dispositivos autoprotectores del paciente, tendientes a preservar aspectos frágiles del self de una retraumatización (Orange et al., 2012). Pero también puede ser que el paciente acepte sin convicción la interpretación del terapeuta, como el precio que debe pagar para no arriesgar el vínculo. Brandschaft llama a esta última alternativa acomodación patológica y es la repetición de esquemas tempranos de sometimiento que se reeditan y que pasan inadvertidos para el analista (Orange et al., 2012).

Es importante que el terapeuta respete al paciente en el sentido inverso al convencional: del que tiene más poder al que tiene menos, que acepte la falibilidad y aliente el reclamo del paciente frente a lo que considere un sesgo interpretativo equivocado, sin ignorarlo ni reinterpretarlo, y que haga participar al paciente de ese proceso que los lleve a una interpretación conjunta. 
Los relacionalistas plantean un encuentro dialógico, franco, espontáneo, natural, con la asimetría estructural lógica de roles diferenciados: alguien que pide ayuda psicológica a alguien que la ofrece. Pero esta asimetría no debe ser un obstáculo para que la relación en la díada sea igualitaria y para que cada uno de sus integrantes se sienta participante habilitado para una creación conjunta de significados psicoanalíticos. La posición objetiva del analista observador, pantalla en blanco, frente a un paciente observado (reforzado con el uso del diván) ha cedido paso a la imagen del psicoterapeuta con una dimensión real y con disponibilidad emocional hacia su paciente como coconstructor igualitario de la relación analítica. Se constituye así un campo intersubjetivo singular, una díada única que pone en interrelación dos organizaciones psíquicas diferentes.

Yo siento lo que es ser tú.

Terapeuta

Yo siento que tú sientes lo que yo siento.

Paciente

Antonio llega a la consulta por un motivo de insatisfacción laboral. Profesional de 57 años, exitoso en una empresa en la que desarrolló su carrera. Desde hace un año se ha sentido desplazado por el ingreso de gente joven con gran dominio de herramientas informáticas que él conoce «ahí nomás». Sin embargo, al poco tiempo sus sesiones comienzan a girar insistentemente en torno a su esposa, con quien lleva «una vida de casados», con dos hijos estudiando en el exterior. Se hacen reiteradas sus quejas: la vida sexual casi inexistente, los gustos diferentes (por ejemplo, los fines de semana él prefiere mirar deportes por cable; ella, salir con parejas que a Antonio no le interesan y comer afuera, porque «cada vez se ocupa menos de la casa»), situaciones todas que motivan reproches 
mutuos, desencuentros... Ese día llega a la sesión y comienza a contar exaltado nuevos conflictos y una última pelea que los tiene desde hace dos días sin dirigirse la palabra. Cuando hace una pausa en su pormenorizado relato, le pregunto con tono reflexivo y voz pausada: «Antonio, ¿qué cree que sostiene su pareja?». Se queda en silencio, como sorprendido, y al cabo de una pausa inusual en él me responde, para mi sorpresa: «¿Sabe que tiene razón?».

«¿Razón?, ¿en qué?», pienso sobresaltada. Yo estaba en mi época psicoanalítica tradicional. No le había dicho ni sugerido nada, me defendí internamente: le había hecho una pregunta abierta (¿para no dejarlo solo?). ¿Qué había escuchado Antonio que yo no dije?

— ¿Razón?, ¿a qué se refiere?

—A eso! A por qué no me separo, por qué sigo al lado de una mujer que no me hace feliz, que siempre está desconforme, que vive quejándose y amargándome la vida.

¡Increíble! Palabras más, palabras menos, Antonio había leído mis pensamientos. Ya estábamos al final de la sesión y me surgió decirle que me parecían muy importantes todas esas preguntas que se hacía y para las cuales seguramente existían respuestas que él no conocía y yo tampoco, pero que íbamos a tratar de descubrir juntos.

A partir de allí algo cambió en ambos: todas esas preguntas que Antonio había podido adivinar en mí a pesar de que yo no las había formulado generaron un nosotros que nos permitió instalarnos en un diálogo amable y productivo. Pudo hablar del desgaste en la pareja, de su propio desgaste, del paso del tiempo y lo que le producía sentir que estaba envejeciendo. Asumió el protagonismo en su dificultad «de reciclarse». 
Siempre me quedó ese momento de inflexión en nuestro vínculo como un gran interrogante. Tuvieron que pasar muchos años para sentirme acompañada en mi inquietud y encontrarme con respuestas:

Nadie podía comenzar a explicar el mecanismo por el que sabemos qué hacen, piensan o sienten los demás. Las neuronas espejo constituyen los cimientos de la empatía. (Iacoboni, 2010, p. 14)

¿Se leen los contenidos mentales del otro? Dos personas ven y sienten casi el mismo paisaje mental por un momento [...]. La psicoterapia consiste principalmente en esos encuentros. (Stern, 2017, p. 63)

¿Una conexión emocional? (Riera, 2011), ¿una sintonización afectiva? (Stern, 2017), ¿el encuentro de nuestras neuronas espejo? Yo había podido sentir el hartazgo y la frustración de Antonio y, luego, ese alivio que surge cuando sentimos que alguien siente lo que sentimos y podemos entonces deponer la batalla por hacernos entender. Antonio me demostró el valor de la conexión emocional, que a veces no surge de manera inmediata y espontánea y que nos obliga a intentar conscientemente ubicarnos en una perspectiva empática: esa superposición homoespacial transitoria que nos permite conocer las emociones del paciente y su circunstancia desde su mente. Y me mostró también la importancia de ir compartiendo esa comprensión con él, para cerciorarnos de que estemos bien encaminados o de que sea necesario recalcular y no dejarlo solo con su angustia.

La comunicación tentativa de la comprensión disminuye la asimetría, tan lesiva especialmente en pacientes con un yo frágil, poco cohesivo (Ornstein y Ornstein, 1998). Hace que el paciente se sienta parte activa del proceso, lo estimula a colaborar y ayuda también a transparentar el curso del pensamiento del terapeuta, lo que le permite entender a aquel 
cómo piensa este, cómo llega a sus interpretaciones, para poder ir apropiándose de a poco de la función analítica.

Paula Heimann (1978) cuestiona el análisis que se basa exclusivamente en interpretaciones, que no permite la formulación de preguntas directas que estimulen lo que ella denomina reacciones asociativas y que, en lugar de esto, espera de forma pasiva a que surjan espontáneamente asociaciones, que a veces no aparecen y dejan al paciente en una soledad no elaborativa, sino desamparada. Preguntar para conocer, no para sorprender o confirmar hipótesis teóricas. No son las teorías las que nos permiten comprender, sino el mantener activo un genuino espíritu de indagación (Lichtenberg, 1991).

Orange (2011) desarrolla y adhiere a la hermenéutica de la confianza propuesta por Hans Gadamer en reemplazo de la hermenéutica de la sospecha, característica de la clínica freudiana. Esto implica partir del supuesto de que ambos - terapeuta y paciente- comparten un mismo objetivo en su búsqueda y confiar en el paciente hasta la credulidad, respetando sus tiempos para ahondar en áreas conflictivas. Estar dispuestos a aprender del paciente, no solo sentir que debemos «iluminarlo», distiende y facilita la creación de un vínculo de confianza, de una base segura que va afirmando su autoestima y lo anima a aproximarse a investigar áreas dolorosas (inconsciente dinámico) al sentirse contenido y acompañado. Vivir una experiencia emocional diferente ayuda a disminuir el temor a repetir y aumenta la esperanza de cambiar.

El objetivo es modificar nuestro conocimiento relacional implícito, nuestra forma de estar con el otro, a través de la creación de un nuevo patrón vincular en la díada terapeuta-paciente - patrón que algunas veces es inédito para ambos-y modificar, así, esa forma automática que adquirimos en nuestra infancia de relacionarnos y de reaccionar emocionalmente. Esas respuestas pobres y desadaptativas persistirán «hasta que nuevas experiencias de relación - $-\mathrm{y}$ no nuevos conocimientos 
ofrecidos a través de interpretaciones- creen nuevos circuitos neuronales que se sobrepongan a los antiguos y los anulen, y puedan aparecer nuevas respuestas y formas de comportamiento» (Coderch de Sans, 2010, p. 122). Se trata de una clínica que jerarquiza el cómo y no solo el qué de los contenidos verbales. El insight surgirá como consecuencia y no como causa del cambio.

Pero no hay técnica ni práctica ni método que pueda prescindir de quién lo lleva a cabo. Es el terapeuta el responsable de crear un ambiente clínico y una matriz de acogida terapéutica para ayudar a ese paciente vulnerable que consulta. El psicoanálisis relacional — que sustituye la uniformidad de reglas clínicas a cumplir por la necesidad de una actitud, una sensibilidad, un posicionamiento empático a adoptar en la interacción con cada paciente- nos replantea más que nunca un debe en la formación teórico-práctica: dirigir también nuestra mirada a la persona del psicoterapeuta.

\section{REFERENCIAS BIBLIOGRÁFICAS}

Bollas, C. (1987). La sombra del objeto: psicoanálisis de lo sabido no pensado. Amorrortu.

Bauman, Z. (2003). La modernidad líquida. Fondo de Cultura Económica.

Coderch de SANS, J. (2010). La práctica de la psicoterapia relacional. Ágora Relacional.

FREUD, S. (1980). Consejos al médico sobre el tratamiento psicoanalítico (1912). En Obras completas (vol. XII, pp. 107-120). Amorrortu. 
Heimann, P. (1978). Sobre la necesidad de que el analista sea natural con su paciente. En J. P. Jiménez (trad.), Provocación y tolerancia (pp. 215-230). Suhrkamp Verlag.

Herskovits, M. (1952). El hombre y sus obras. La ciencia de la antropología cultural. Fondo de Cultura Económica.

IACOBOnI, M. (2010). Las neuronas espejo. Katz.

LichtenBerg, J. (1991). El modo de percepción empático y perspectivas alternativas para el trabajo psicoanalítico. Revista de Asociación Escuela Argentina para Graduados, 17.

Mitchell, S. (2015). Influencia y autonomía en Psicoanálisis. Ágora Relacional.

Orange, D. (2013). El desconocido que sufre. Cuatro Vientos.

Orange, D., Atwood, G. y Storolow, R. (2012). Trabajando intersubjetivamente. Contextualismo en la práctica psicoanalitica. Ágora Relacional. Ornstein, A. y Ornstein, P. (1998). Empatía y diálogo terapéutico. En Anuario de la Psicología del Self, 3. Universidad Católica Argentina. RIERA, R. (2011). La conexión emocional: Cómo se forma nuestra manera espontánea y no voluntaria de reaccionar emocionalmente. Octaedro.

SteRn, D. (2017). El momento presente. Cuatro Vientos.

Stolorow, R. y Atwood, G. (2004). Los contextos del ser. Herder. 